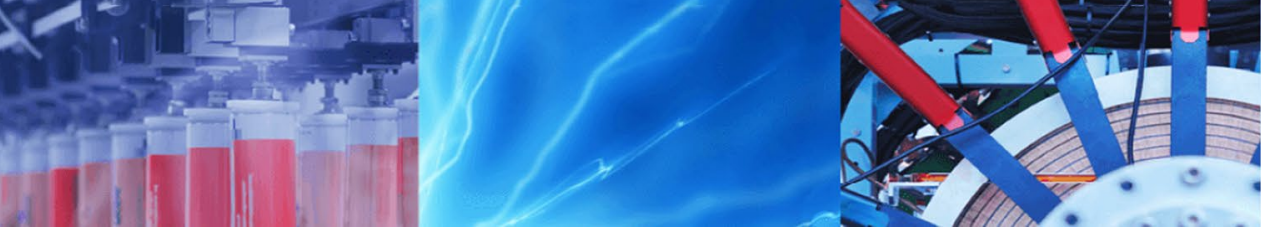

Research Article

\title{
Investigation on the effect of cryogenic treatment on tungsten carbide milling insert with $11 \%$ cobalt (WC-11\%Co)
}

\author{
M. Padmakumar ${ }^{1}$ D $\cdot$ D. Dinakaran ${ }^{2}$
}

Received: 23 March 2020 / Accepted: 3 May 2020 / Published online: 9 May 2020

(c) Springer Nature Switzerland AG 2020

\begin{abstract}
The objective of this research is to evaluate the performance of cryogenically treated cemented carbide milling inserts with $11 \%$ cobalt content in face milling of EN19 steel. Two different deep cryogenic treatments at temperature of around $-193^{\circ} \mathrm{C}$ were performed on the inserts, namely cryogenic treatment and cryogenic treatment and tempering. Uncoated tungsten carbide face milling inserts with $11 \%$ cobalt content were used in this research. Machining tests were conducted at the catalog recommended cutting parameters, and flank wear and nose wear of untreated, cryogenically treated and cryogenically treated and tempered inserts were compared to study the performance. The experimental investigation revealed that both cryogenic treated and cryogenic treated and tempered inserts showed $4-7 \%$ lesser flank and nose wear than the untreated inserts. The metallurgical examinations using indirect measurement technique revealed the phase transformation of cobalt from FCC to HCP which could have resulted in increased hardness, reduced friction coefficient and improved tool life.
\end{abstract}

Keywords Cryogenic treatment · Face milling · Tungsten carbide · Phase transformation · Tool life

\section{Introduction}

Cryogenic treatment is carried out to metals to change the microstructure and hence improve the mechanical properties. It is widely accepted that like heat treatment, cryogenic treatment improves the properties of ferrous materials [1]. But the commercial adoptability of the process is in initial stage for the super hard tool materials like tungsten carbide due to lack of proven scientific researches. Early researchers were uncertain about the process as tungsten carbide with a Mohs scale value of 9-9.5 lies just below diamond in the hardness scale and is highly stable to most of the post processing treatments.

Heat treatment is carried out to metals to induce phase transformation. In the case of steel, diffusion-based transformation results in formation of pearlitic structure, whereas diffusion-less transformation forms martensitic structure [2]. When steel is heat-treated and quenched, due to the improper quenching parameters some austenite does not get transformed to martensite and remains as retained austenite [3]. Cryogenic treatment assists in transforming the austenitic phase (ductile phase) into harder martensitic phase [1]. Similar martensitic phase transformation was observed by many researchers when steel is cryogenically treated [1]. A research carried out by Bensely et al. [4] in the case-carburized En 353 steel shows that deep cryogenically treated samples showed $85 \%$ and $372 \%$ better wear resistance than the untreated samples. The microstructural evaluation revealed that the retained austenite found in the heat-treated samples was absent in the cryogenically treated samples. They got transformed to martensite which increased the hardness.

Similar observation was made by Collins and Dormer [5] on D2 tool steel. Apart from phase transformation, they

M. Padmakumar, Padmakumar.Muthuswamy@kennametal.com | ${ }^{1}$ Technology Centre, Kennametal India Ltd, Bangalore 560073, India. ${ }^{2}$ Centre for Automation and Robotics, Hindustan Institute of Technology and Science, Chennai 603103, India. 
have also observed that fine carbides were precipitated in the cryogenically treated samples. In a study conducted by Zhirafar et al. [6] they have observed that hardness and the fatigue strength of cryogenically treated AISI 4340 steel showed a significant improvement. The treatment's success in steel made the researchers to test the process on tungsten carbide (WC-Co) tools.

Kalsi et al. [7] have shown that cryogenically treated tungsten carbide tools exhibited improvement in the flank wear resistance and gave better surface finish. They have proved this by performing cylindrical turning using untreated and treated inserts. Yan et al. [8] observed a rise in the hardness and wear resistance of tungsten carbide inserts that were treated cryogenically. Similar improvement in the wear resistance was also observed by Dinesh et al. [9]. Sreerama Reddy et al. [10] have observed that cutting forces of cryogenically treated tungsten carbide inserts were lower and it also gave better surface finish than the untreated inserts while performing turning.

Yong and Ding [11] has proved that cryogenic treatment improves the compressive strength and fatigue strength of cemented carbide tools without affecting the toughness and bending strength. They have found that the treatment also increases the hardness and wear resistance significantly. Nursel et al. [12] have observed an improvement of $34 \%$ in the flank wear resistance at cutting speed of $100 \mathrm{~m} / \mathrm{min}$ while performing cylindrical turning operation. The performance improvement was 16\%, 17\% and $27 \%$ when the cutting speed was 120,140 and $160 \mathrm{~m} /$ min, respectively. Turning experiments with untreated WC-9Co inserts showed a significant improvement in flank and nose wear resistance of the treated inserts [13].

In metal cutting operations like turning, the load acting on the tool is uniform without any major fluctuations, whereas, in the case of operations like milling, the load is cyclic. The tool experiences recurring heating and cooling along with the interrupted shock loads acting on it. Most of the researchers studied the performance of cryogenic treated tungsten carbide in turning operation. But there is a gap in the literature in understanding the performance in unfavorable cutting condition like milling. The gap is addressed in this paper by studying the cryogenic treatment effect on cemented carbide inserts on face milling operation. Uncoated milling inserts with high cobalt content of around $11 \%$ were chosen for the study to avoid the influence of coating variables (coating thickness, coating imperfections, etc.) on the performance. The magnetic properties of the inserts were studied to understand the factors that influenced the changes in performance.

\section{Experimental procedure}

\subsection{Machining condition}

Face milling operation was carried out on a standard EN19 steel block of size $300 \mathrm{~mm} \times 150 \mathrm{~mm} \times 150 \mathrm{~mm}$ (length $\times$ width $\times$ thickness) with hardness of around $220 \mathrm{BHN}$. Cutting parameters like cutting speed, feed per tooth, depth of cut and radial engagement were selected as recommended in the Widia milling catalog [14].

Widia face milling cutter of $80 \mathrm{~mm}$ diameter with 5 pockets was used for the testing. Fly cutting strategy (only one of the pockets is mounted with cutting insert) was used for the tool life testing at $140 \mathrm{~m} / \mathrm{min}$ cutting speed, $0.1 \mathrm{~mm} /$ tooth feed rate, $2 \mathrm{~mm}$ axial depth of cut and $38 \mathrm{~mm}$ radial engagement on MAZAK FJV-200 machining center. As milling is an interrupted-type cutting operation where heating and cooling of insert happen in a cyclic manner, to avoid further fluctuations in the thermal load, coolant was not used for the testing.

\subsection{Cryogenic treatment}

All the modern cryogenic treatment applied for metals is a dry treatment or noncontact-type treatment process where the cryogen used for cooling does not meet the metal being treated. This is important as a direct contact between the cryogen and the tool samples could result in the formation of cold cracks. For the study, liquid nitrogen was used as the cryogen using which it is possible to go down up to $-196^{\circ} \mathrm{C}$. A cryogenic chamber resembles a household refrigerator in which the samples are placed for processing. The temperature inside the chamber and the rate of cooling are controlled precisely using computer software. Cooling and warming rate adopted for the study were set as $0.25^{\circ} \mathrm{C} / \mathrm{min}$ and $0.15^{\circ} \mathrm{C} / \mathrm{min}$, respectively. This ensures that the thermal load acting on the samples is slow and gradual. The three major steps that were involved in the cryogenic treatment are as follows,

- Step 1 Samples are cooled to $-193^{\circ} \mathrm{C}$ from room temperature at $0.25^{\circ} \mathrm{C} / \mathrm{min}$.

- Step 2 Samples are soaked at this temperature for around $27 \mathrm{~h}$ to allow the metallurgical changes to happen.

- Step 3 Samples are warmed back to room temperature at $0.15^{\circ} \mathrm{C} / \mathrm{min}$. This completes the cryogenic treatment process. For few samples, additional step 4 was included.

- Step 4 (Tempering) Samples are removed from the cryogenic chamber and placed in a furnace. They 
are heated to $200^{\circ} \mathrm{C}$ and were brought back to room temperature slowly. Tempering is done to relieve the stresses and stabilize the samples. The approximate time taken for this tempering cycle was around $1 \mathrm{~h}$. Tempering temperature and duration of tempering were selected based on the literature survey $[7,12$, $15,16]$.

The cryogenic treatment cycle followed for the study is shown in graphical form in Fig. 1.

\subsection{Face milling operation}

Commercially available uncoated Widia face milling inserts (SPKN1504EDR) with $11 \%$ cobalt content were procured for the study. The inserts were split into three different batches. The first batch of inserts was retained as the untreated (UT) samples for the benchmark comparison. The second batch of inserts was treated with cryogenic treatment (CT) alone. The third batch of inserts was cryogenically treated and tempered (CTT).

All the three batches of inserts were cleaned thoroughly using acetone for removing dust and impurities from the surface. The inserts were then examined under an optical microscope of $30 \times$ resolution to check for defects like edge chipping, edge deformation and irregular honing. It is very important to ensure that the edges of untreated and treated inserts are uniform, as even a minor change in the edge condition would have a higher impact on the wear rate. The edge hone of all the three inserts was measured using a contour tracer, and the inserts with similar hone values were only used for the testing. The face milling cutter and the insert used for the study are shown in Fig. 2.

As shown in Fig. 2, firstly the untreated insert was loaded in the cutter pocket and clamped to the recommended torque. Only single insert was mounted over the cutter (fly cutting) for the face milling operation to eliminate the effect of axial and radial run-out on the flank and nose wear.

The cutter was then mounted on the milling machine, and the face milling operation was performed on the rectangular workpiece. Wear value was set as $0.5 \mathrm{~mm}$ for both the flank and nose wear so that when any of the

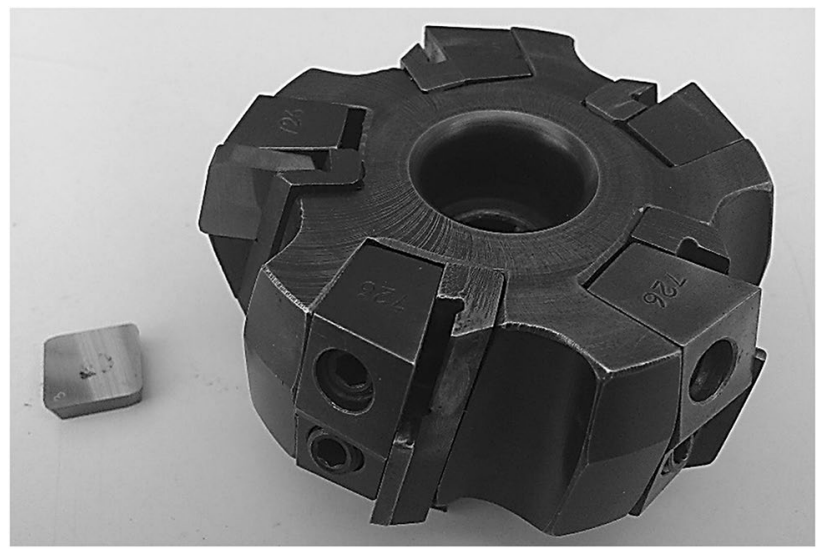

Fig. 2 Face milling cutter and insert used for the study
Fig. 1 Cryogenic treatment process

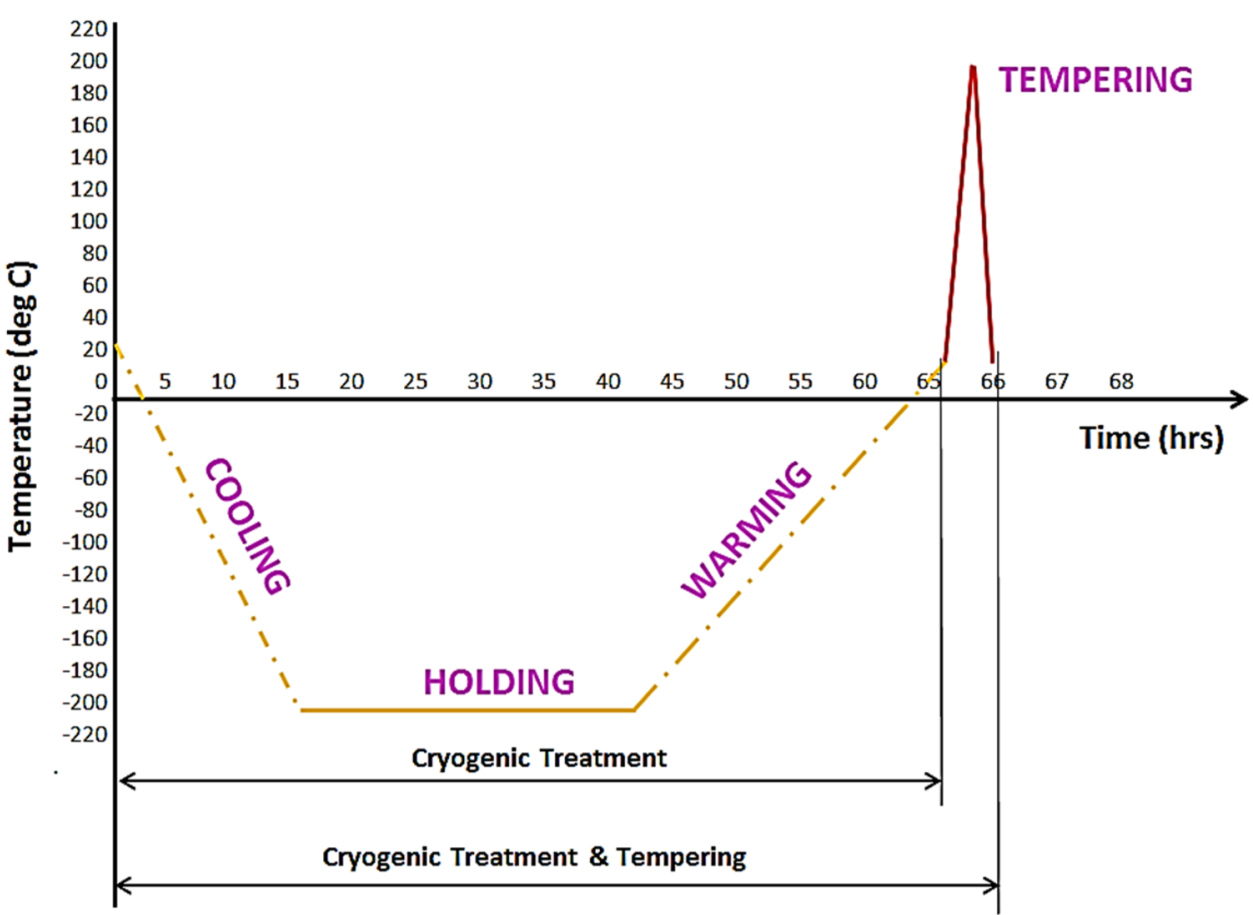

SN Applied Sciences A SPRINGER NATURE journal 
wear reaches the set limit, the test would be stopped. Flank and nose wear on the insert were measured at the end of every 2 passes. Machining length of $300 \mathrm{~mm}$, width of $37.5 \mathrm{~mm}$ and depth of $2 \mathrm{~mm}$ are machined in a single pass. Each experiment was repeated twice to avoid random errors, and the results of the first repetition are reported here.

\section{Results and discussion}

\subsection{Metal cutting tests}

According to ANSI/ASME B94.55 M-1985 standard [17], the major cutting edge of a single-point cutting insert is divided into Zone $C$ (curved part of the edge at the nose), Zone $\mathrm{N}$ (quarter of the worn cutting-edge length between farthest from the tool corner) and Zone B (straight part of the cutting edge between Zone $\mathrm{C}$ and $\mathrm{N}$ ) as shown in Fig. 3.
Based on the recommendation, $\mathrm{VB}_{\mathrm{Bmax}}$ and $\mathrm{VB}_{\mathrm{C}}$ were taken as the flank and nose wear for analyzing the tool life, respectively.

The flank and nose wear values of the inserts measured using Nikon MM-400 optical microscope with a $30 \times$ resolution taken at a fixed interval of 2 passes ( $80 \mathrm{~s}$ ) were tabulated as shown in Table 1.

As seen from Table 1 and Fig. 4 the cryogenically treated and tempered insert (CTT) showed lesser flank and nose wear at the end of 2 nd pass ( $80 \mathrm{~s}$ of machining time), whereas there is no change in the wear of un-tempered (CT) insert when compared to the untreated insert. Usually, the wear of tools measured at initial few minutes of machining is insufficient to predict the behavior as the tool takes some time to adjust to the machining condition. Random factors like microscopic-level variation in the cutting-edge geometry or position of the insert on the tool holder would get adjusted by itself as the machining progresses. In the turning experiments performed by Nursel et al. [12] and Simranpreet et al. [18] to compare the performance of untreated and cryo-treated tungsten
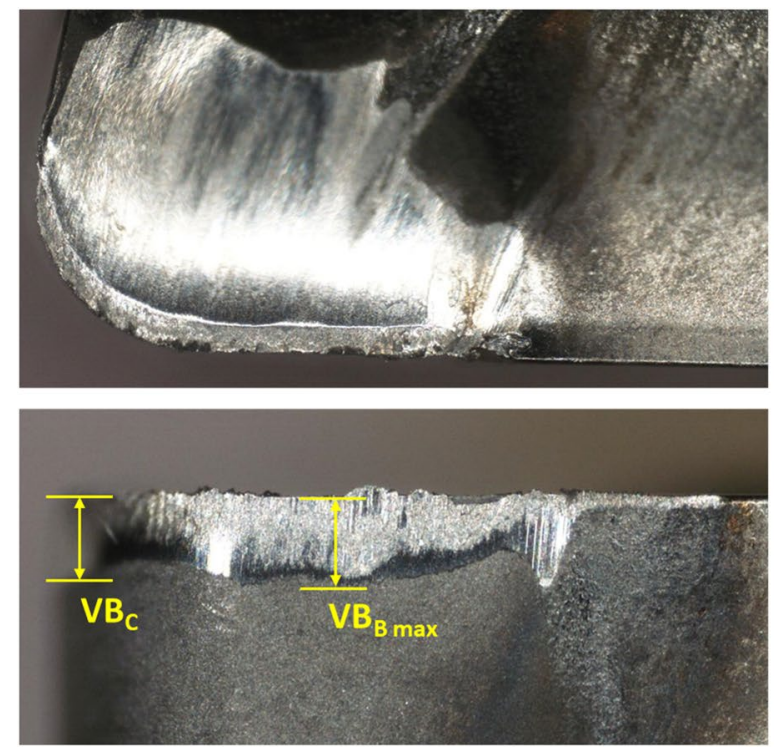

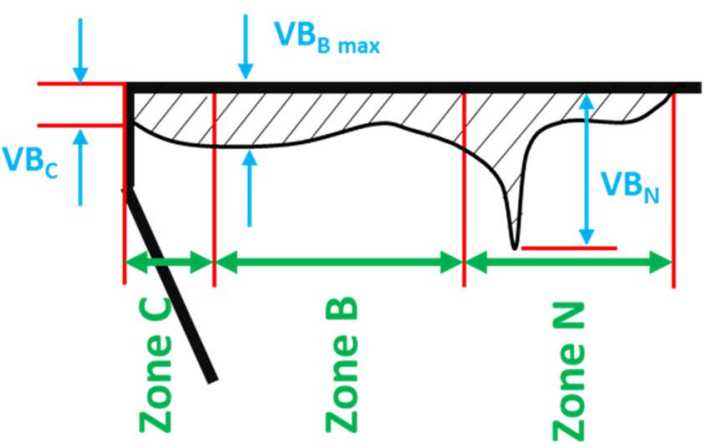

Fig. 3 Flank wear characteristics according to ANSI/ASME B.94.55 M-1985 standard

Table 1 Flank and nose wear of untreated and cryogenic treated inserts

\begin{tabular}{|c|c|c|c|c|c|c|c|}
\hline \multirow[t]{2}{*}{ Passes } & \multirow[t]{2}{*}{$\begin{array}{l}\text { Machining } \\
\text { time (s) }\end{array}$} & \multicolumn{2}{|l|}{ Untreated (UT) } & \multicolumn{2}{|c|}{ Cryogenic treated $(\mathrm{CT})$} & \multicolumn{2}{|c|}{$\begin{array}{l}\text { Cryogenic treated and tempered } \\
\text { (CTT) }\end{array}$} \\
\hline & & Flank wear (mm) & Nose wear (mm) & Flank wear (mm) & Nose wear (mm) & Flank wear (mm) & Nose wear $(\mathrm{mm})$ \\
\hline 2 & 80 & 0.380 & 0.280 & 0.380 & 0.280 & 0.335 & 0.256 \\
\hline 4 & 160 & 0.430 & 0.380 & 0.420 & 0.330 & 0.420 & 0.340 \\
\hline 6 & 240 & 0.470 & 0.410 & 0.470 & 0.340 & 0.475 & 0.377 \\
\hline 8 & 320 & 0.530 & 0.470 & 0.505 & 0.440 & 0.510 & 0.450 \\
\hline
\end{tabular}



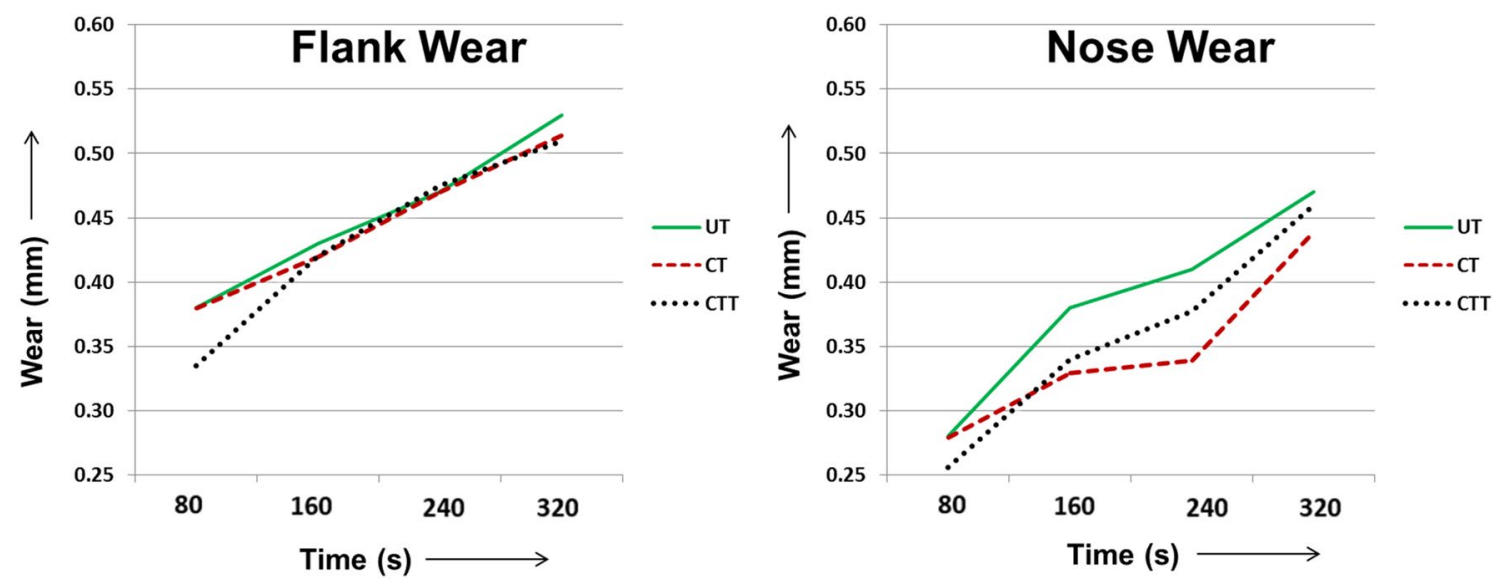

Fig. 4 Graphical representation of flank and nose wear

carbide inserts they have observed a similar behavior. The difference in the flank and nose wear of the treated and untreated inserts during the initial stage of machining was either minimal or naught. But a performance improvement of around $34 \%, 53 \%$ and $69 \%$ in terms of flank, crater and notch wear rate was seen at the end of the test [12].

The flank wear values at the end of 4th and 6 th pass (160 and $240 \mathrm{~s}$ ) of all the three inserts showed a negligible difference. However, the nose wear showed a clear improvement in the wear resistance of cryo-treated and cryo-treated and tempered inserts. At the end of 8th pass (320 s), both the treated inserts showed better flank wear resistance than the untreated insert. It was seen that cryogenic treated and cryogenic treated and tempered insert showed $5 \%$ and $3.9 \%$ better flank wear resistance than the untreated insert. Similarly, $6.8 \%$ and $4.5 \%$ better nose wear resistance was seen for the cryogenic treated and cryogenic treated and tempered insert when compared to the untreated insert. There is no difference in the flank wear of both the treated inserts, whereas the un-tempered inserts (CT) showed slightly lesser nose wear than the tempered (CTT) inserts. Tempering is a stress-relieving process usually performed after heat treatment which was being followed for cryogenic treatment as well. Nirmal et al. [19] have reported that tempering helps in stabilizing the tungsten carbide material, but increasing the number of tempering cycles reduces the hardness. However, Abdullah et al. [16] have shown that tempering reverses the martensitic phase transformation which proves that optimum tempering process exists for WC-Co hardmetals based on its composition. So, tempering after cryogenic treatment would have had a slight negative effect on the metallurgical properties that resulted in marginally higher nose wear. As enough data points were captured and the wear on the inserts have exceeded the recommended wear, the test was concluded.
However, the rate of performance improvement was minimal when compared to the enhancement reported by other researchers. This shows that there could be an optimum cryogenic process parameter for different tools based on the composition, grain size or microstructure which must be explored further. Figure 4 shows the flank and nose wear of the inserts in a graphical form for easy understanding and comparison.

The flank and nose wear photographs taken under $30 x$ resolution are shown in Fig. 5. The images are shown for the wear comparison between the untreated, cryogenic treated and cryogenic treated and tempered insert taken at the measured interval.

From the microscopic images it can be observed that apart from uniform flank and nose wear, none of the inserts have shown any other abnormal wear patterns like microchipping, notching or cratering (as seen in 50x magnification in Fig. 5). As the selected milling inserts were with $11 \%$ cobalt content which comes under high cobalt grade for metal cutting standards, the inserts are tougher for cracks, microchipping or notching, the failure modes which are commonly seen in low cobalt and harder grades [20]. The low cutting speed which was intentionally selected as the inserts were uncoated might have assisted the tool in avoiding further complex wear mechanisms. From Table 1, Figs. 4 and 5 it was also clear that cryogenic treated inserts exhibit lesser flank and nose wear when compared to the untreated insert.

\subsection{Metallurgical evaluation}

With a melting point of around $2900^{\circ} \mathrm{C}$, tungsten carbide is highly stable, and it does not easily react to thermal treatments (like heat treatment or cryogenic treatment); however, cobalt with relatively lower transition temperature makes it a viable candidate to study the changes in 


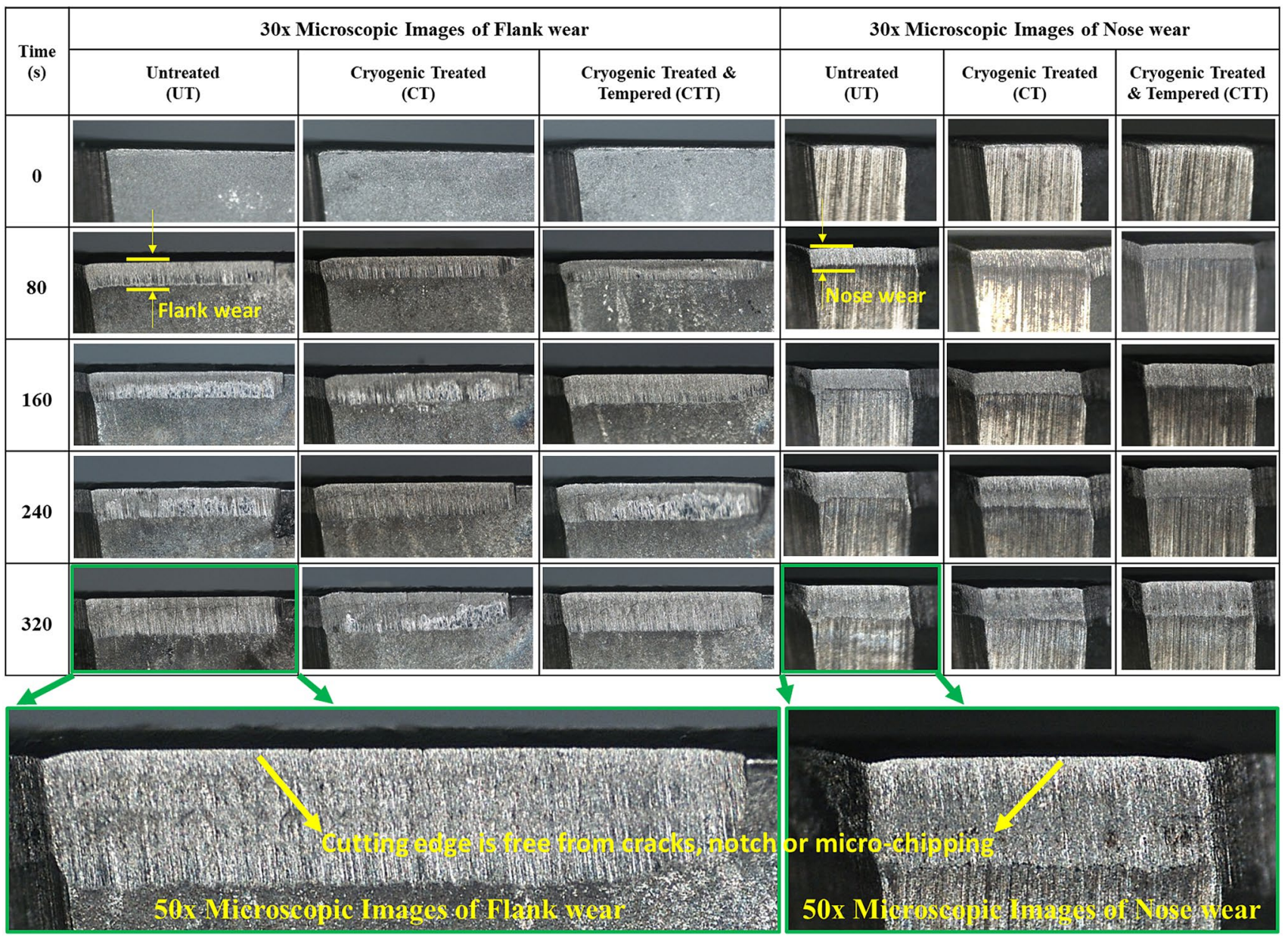

Fig. 5 Microscopic images of flank and nose wear

metallurgical properties. X-ray diffraction analysis (XRD) is the most commonly used technique to study the phase structure of crystalline material, and hence, the samples were subjected to the examination. PANalytical Empyrean Series 2 XRD unit was used to analyze the change in crystal structure of the samples. But, the XRD spectrum of the untreated and treated inserts showed no change.

Researchers have proven that due to very low volumetric composition of cobalt present in tungsten carbide tools, the high-intensity peaks of tungsten carbide mask the cobalt peaks which make it impossible to study the phase structure of cobalt $[15,21,27]$. To clearly see the peaks of different cobalt phases the amount of cobalt must be at least 40\% [21]. In Fig. 6, the peaks of $a-C o$ and $\varepsilon$-Co started appearing only in the samples with $20 \%$ cobalt and the intensity of the peak is stronger for the samples with $40 \%$ and $80 \%$ cobalt.

So, unconventional measurement techniques were used to evaluate the changes in microstructure and metallurgical properties. Hence, magnetic saturation and coercivity tests, the two important nondestructive techniques used to study the properties of cobalt present in a tungsten carbide tools, were performed on the untreated and cryo-treated samples according to ASTM B-886 and ASTM B-887 standards to study the microstructural changes.

The average magnetic saturation and coercivity values of 5 untreated and cryo-treated samples are tabulated in Table 2.

Magnetic saturation depends on the carbon content and solubility of tungsten in cobalt in WC-Co alloys (which is determined by studying the changes in ferromagnetic cobalt binder), whereas coercive force depends on the grain size, composition and distribution of cobalt. The unchanged magnetic saturation values show that there is no change in the carbon content and hence eta-phase carbides are not precipitated in the cryo-treated inserts. As eta is nonmagnetic, the precipitation of the phase would have resulted in changes in magnetic saturation value. The improvement in coercivity shows that the phase transformation of cobalt from FCC to HCP phase has occurred after cryo-treatment.

\section{SN Applied Sciences



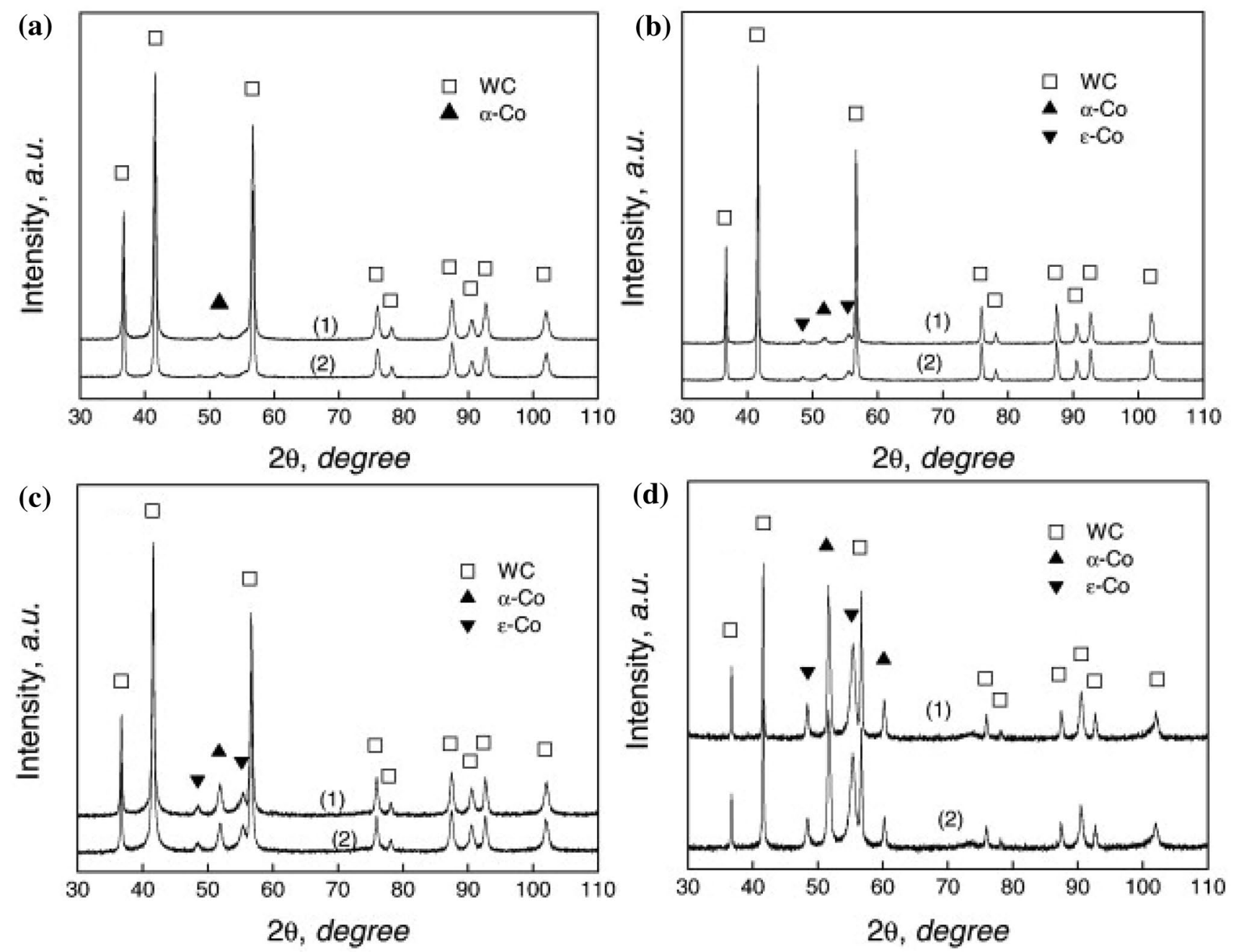

Fig. 6 XRD spectrum of untreated (line 1) and cryo-treated (line 2) tungsten carbide with: a 12\% Co, b 20\% Co, c 40\% Co, d 80\% Co [21]

Table 2 Magnetic saturation and coercivity of WC-11Co

\begin{tabular}{lll}
\hline Treatment state & $\begin{array}{l}\text { Coercivity, } \mathrm{Hc} \\
(\mathrm{kA} / \mathrm{m})\end{array}$ & $\begin{array}{l}\text { Magnetic satura- } \\
\text { tion, } \mathrm{Ms}\left(\mu \mathrm{Tm}^{3} /\right. \\
\mathrm{kg})\end{array}$ \\
\hline Untreated & 11.53 & 19.7 \\
Cryogenic treated & 11.88 & 19.7 \\
Cryogenic treated and & 11.87 & 19.7 \\
tempered & & \\
\hline
\end{tabular}

Literature shows that precipitation of carbides and martensitic phase transformation [22-24] are the factors behind the performance improvement in cryogenic treated steel and its alloys. The crystal structure of cobalt in a sintered WC-Co hardmetal has both FCC and HCP structure. Like iron, as cobalt, a key element used as a binder in the manufacturing of cemented carbide tools is ferromagnetic, the phase transformation (from FCC to $\mathrm{HCP}$ ) would occur for it as well which would have played a key role in increasing the hardness and hence the performance improvement. Phase transformation of cobalt in cryo-treated tungsten carbide tools was seen by other researchers as well $[15,16,25-27]$ which resulted in slight increase in the hardness and improved wear resistance.

To identify the cobalt phases in tungsten carbide through XRD, the amount of cobalt present in the sample must be more than $25 \%$ as anything lesser than that would result in cobalt peaks overlapping or shielded by tungsten carbide peaks $[15,21]$. So, it is hypothesized that the transformation of cobalt from FCC to HCP structure resulted in improved tool life. An increase in the coercive force value and a corresponding improvement in the wear properties of WC-Co hardmetal were seen by other researchers as well $[28,29]$. The presence of higher slip system in cubic lattices makes the material ductile. Lesser slip system in HCP-cobalt $(\varepsilon-\mathrm{Co})$ when compared to FCC-cobalt ( $\mathrm{a}-\mathrm{Co})$ makes the material hard to deform [30]. Also, the friction coefficient of $\varepsilon$-Co is lesser which means that the tool 
would be less prone to breakage and fracture [31]. The increase in hardness and reduced friction coefficient due to the phase transformation would have given favorable properties to the tool which resulted in slightly higher wear resistance.

\section{Conclusions}

The experimental investigation carried out on EN19 steel using cryogenically treated and cryogenically treated and tempered inserts gave the following conclusions,

- For the selected cryogenic process parameters and under the chosen machining condition, cryogenic treated (CT) insert showed $5 \%$ lesser flank wear and $6.8 \%$ lesser nose wear on assessment with the inserts that are untreated. Cryogenic treated and tempered (CTT) insert showed 3.9\% lesser flank wear and $4.5 \%$ lesser nose wear when compared against the inserts that are untreated.

- Tempering after cryogenic treatment resulted in a slight decrease in the flank and nose wear resistance when compared to the untempered insert. The metallurgical evaluation using indirect techniques revealed the phase transformation of cobalt which contributed to the performance improvement.

- The improvement in flank and nose wear of treated inserts is marginal which could be due to the low cobalt content. Cryo-treatment influences only the cobalt phase, and as there is no change in the tungsten carbide phase, for a tool with low cobalt content the scope for improvement is also low. So higher-performance improvement could be seen in high cobalt content tungsten carbide samples.

In future, the untreated and treated inserts will also be tested in other commonly used work material like cast iron to study and compare the performance of the tools in machining brittle materials.

Acknowledgements The authors acknowledge the contribution of staffs at Technology Center, Metal Cutting Laboratory and Metallurgical Laboratory, Kennametal India Ltd., Bangalore, for their excellent support and extending their testing facilities to carry out this research.

Authors' contribution Dr PM made substantial contributions to conception and design, acquisition of data, analysis and interpretation of data and drafting the manuscript. Dr DD made substantial contributions to conception and design and drafting the manuscript.

Availability of data and material The datasets supporting the conclusions of this article are included within the article.

\section{Compliance with ethical standards}

Conflict of interest The authors have no competing interests to declare.

\section{References}

1. Akincioğlu S, Gökkaya H, Uygur I (2015) A review of cryogenic treatment on cutting tools. Int J Adv Manuf Technol 78:16091627. https://doi.org/10.1007/s00170-014-6755-x

2. Shimizu N, Tamura I (1977) An examination of the relation between quench-hardening behavior of steel and cooling curve in oil. Trans Iron Steel Inst Jpn 18:445-450

3. Banerjee MK (2017) 2.1 Fundamentals of heat treating metals and alloys. In: Hashmi MSJ (ed) Comprehensive materials finishing. Elsevier, pp 1-49. https://doi.org/10.1016/B978-0-12-80358 1-8.09185-2

4. Bensely A, Prabhakaran A, Mohan Lal D, Nagarajan G (2005) Enhancing the wear resistance of case carburized steel (En 353) by cryogenic treatment. Cryogenics 45(12):747-754. https://doi. org/10.1016/j.cryogenics.2005.10.004

5. Collins DN, Dormer J (1997) Deep cryogenic treatment of a D2 cold work tool steel. Heat Treat Met 3:71-74

6. Zhirafar S, Rezaeian A, Pugh M (2007) Effect of cryogenic treatment on the mechanical properties of 4340 steel. J Mater Process Technol 186(1-3):298-303. ISSN 0924-0136. https://doi. org/10.1016/j.jmatprotec.2006.12.046

7. Kalsi NS, Sehgal R, Sharma VS (2011) Comparative study to analyze the effect of tempering during cryogenic treatment of tungsten carbide tools in turning. Adv Mater Res 410:267. https ://doi.org/10.4028/www.scientific.net/AMR.410.267

8. Yan H, Xu H, Luo X (2010) The research on process of deep cryogenic treatment for YT15 carbide insert. In: International conference on machine vision and human-machine interface. Kaifeng, pp 725-728. https://doi.org/10.1109/mvhi.2010.28

9. Thakur D, Ramamoorthy B, Vijayaraghavan L (2008) Influence of different post treatments on tungsten carbide-cobalt inserts. Mater Lett 62(28):4403-4406. https://doi.org/10.1016/j.matle t.2008.07.043

10. SreeramaReddy TV, Sornakumar T, VenkataramaReddy M, Venkatram R (2009) Machinability of C45 steel with deep cryogenic treated tungsten carbide cutting tool inserts. Int J Refract Met Hard Mater 27(1):181-185. https://doi.org/10.1016/j.ijrmh m.2008.04.007

11. Yong J, Ding C (2011) Effect of cryogenic treatment on WC-Co cemented carbides. Mater Sci Eng A 528(3):1735-1739. ISSN 0921-5093. https://doi.org/10.1016/j.msea.2010.11.009

12. Özbek NA, Çiçek A, Gülesin M, Özbek O (2016) Effect of cutting conditions on wear performance of cryogenically treated tungsten carbide inserts in dry turning of stainless steel. Tribol Int 94:223-233. https://doi.org/10.1016/j.triboint.2015.08.024

13. Padmakumar M, Dinakaran D, Guruprasath J (2018) Tribological behaviour of cryogenically treated WC-9Co cemented carbide. Mater Today Proc 5(2):7797-7807. https://doi.org/10.1016/j. matpr.2017.11.458

14. Widia (2008) Milling cutters, drills and tooling systems catalog 1:128-129

15. Padmakumar $M$, Guruprasath J, Achuthan P, Dinakaran D (2018) Investigation of phase structure of cobalt and its effect in WC-Co cemented carbides before and after deep cryogenic treatment. Int J Refract Met Hard Mater 74:87-92. https://doi. org/10.1016/j.jijmhm.2018.03.010 
16. Sert A, Celik ON (2019) Characterization of the mechanism of cryogenic treatment on the microstructural changes in tungsten carbide cutting tools. Mater Charact 150:1-7. https://doi. org/10.1016/j.matchar.2019.02.006

17. ANSI/ASME B94.55 M-1985, tool life testing with single-point turning tools

18. Gill SS, Singh R, Singh H, Singh J (2009) Wear behaviour of cryogenically treated tungsten carbide inserts under dry and wet turning conditions. Int J Mach Tools Manuf 49(3-4):256-260. https://doi.org/10.1016/j.ijmachtools.2008.11.001

19. Kalsi NS, Sehgal R, Sharma VS (2014) Effect of tempering after cryogenic treatment of tungsten carbide-cobalt bounded inserts. Bull Mater Sci 37(2):327-335. https://doi.org/10.1007/ s12034-014-0634-9

20. Padmakumar M, Dinakaran D, Ravikumar SG, Vijay Sekar KS (2015) Performance evaluation of cryogenically treated tungsten carbide insert on face milling of grey cast iron. Appl Mech Mater 813-814:569-574. https://doi.org/10.4028/www.scientific .net/AMM.813-814.569

21. Zhang H, Chen L, Sun J, Wang W, Wang Q (2015) An investigation of cobalt phase structure in WC-Co cemented carbides before and after deep cryogenic treatment. Int J Refract Met Hard Mater 51:201-206. https://doi.org/10.1016/j.ijrmhm.2015.04.007

22. Mohan Lal D, Renganarayanan S, Kalanidhi A (2001) Cryogenic treatment to augment wear resistance of tool and die steels. Cryogenics 41(3):149-155. ISSN 0011-2275. https://doi. org/10.1016/S0011-2275(01)00065-0

23. Yang H-S, Jun W, Bao-Luo S, Hao-Huai L, Sheng-Ji G, Si-Jiu H (2006) Effect of cryogenic treatment on the matrix structure and abrasion resistance of white cast iron subjected to destabilization treatment. Wear 261(10):1150-1154. ISSN 0043-1648. https ://doi.org/10.1016/j.wear.2006.03.021

24. Prieto G, Perez Ipiña JE, Tuckart WR (2014) Cryogenic treatments on AISI 420 stainless steel: microstructure and mechanical properties. Mater Sci Eng, A 605:236-243. https://doi.org/10.1016/j. msea.2014.03.059
25. Padmakumar M, Dinakaran D, Guruprasath J (2017) Characterization of cryogenically treated cemented carbide. Integr Ferroelectr 185:65-72. https://doi.org/10.1080/10584587.2017.13703 40

26. Padmakumar M, Dinakaran D (2017) Performance evaluation of cryogenically treated and tempered tungsten carbide insert on face milling of grey cast iron. Int J Mach Mach Mater 19(2):180 191. https://doi.org/10.1504/IJMMM.2017.082910

27. Padmakumar M, Guruprasath J, Dinakaran D (2019) Influence of cryo-processing on properties of tungsten carbide with low, medium and high cobalt content. Mater Res Express 6(10):119601. https://doi.org/10.1088/2053-1591/ab3c97

28. Weng Z, Gu K, Wang K et al (2019) Effect of deep cryogenic treatment on the fracture toughness and wear resistance of WC-Co cemented carbides. Int J Refract Met Hard Mater 85:1. https:// doi.org/10.1016/j.ijrmhm.2019.105059

29. Gu L, Huang J, Tang $Y$ et al (2015) Influence of different post treatments on microstructure and properties of WC-Co cemented carbides. J Alloys Compd 620:116-119. https://doi. org/10.1016/j.jallcom.2014.09.100

30. Zhang H, Chen L, Sun J, Wang W, Wang Q (2014) Influence of deep cryogenic treatment on microstructures and mechanical properties of an ultrafine-grained WC-12Co cemented carbide. Acta Metall Sin (Engl Lett) 27(5):894-900. https://doi. org/10.1007/s40195-014-0134-3

31. Cabrol E, Boher C, Vidal V, Rezaï-Aria F, Touratier F (2019) A correlation between tribological behavior and crystal structure of cobalt-based hardfacings. Wear 426-427(Part B):996-1007. https://doi.org/10.1016/j.wear.2019.01.091

Publisher's Note Springer Nature remains neutral with regard to jurisdictional claims in published maps and institutional affiliations. 